\title{
Identification of base erosion and profit shifting using tax evasion rate
}

\author{
MICHAL FRIEDRICH* (1) and JANA TEPPEROVA
}

Department of Public Finance, Prague University of Economics and Business, Prague, Czech Republic

Received: July 9, 2020 • Revised manuscript received: September 25, 2020 • Accepted: October 2, 2020

Published online: November 6, 2020

(C) 2020 The Author(s)

\begin{abstract}
Multinational enterprises (MNEs) use different methods and structures for base erosion and profit shifting (BEPS) to optimize the tax liability of the group. It is of great interest to the relevant countries to be able to identify such practices and react with appropriate measures. The objective of this paper is to verify whether selected MNEs engaged in the digital economy tend to shift profits from the Czech Republic to jurisdictions with lower taxation using the tax evasion rate (TER) indicator and the transactional net margin method (TNNM). Since the TER method has not been tested yet, this paper also aims to demonstrate its application on real world data and to evaluate its usability. On a sample of five MNEs, the analysis showed a potential tendency to shift profits within Europe for four MNEs (Amazon, Apple, Google and Uber) and a potential tendency to shift profits specifically from the Czech Republic for one MNE (Amazon). The analysis shows that TER is suitable as a preliminary indication of possible risks, rather than their exact quantification.
\end{abstract}

\section{KEYWORDS}

base erosion and profit shifting, tax avoidance, multinational enterprises, transfer pricing, transactional net margin method

${ }^{*}$ Corresponding author. E-mail: michal.friedrich@icloud.com

The paper was prepared as one of the outputs of a research project of the Faculty of Finance and Accounting at the University of Economics "Economic and institutional aspects of public finance" registered by the Internal Grant Agency of the Prague University of Economics and Business under the registration number F1/7/2019 and as an output of the research project "Fair corporate taxation: Measurement of the impact of the corporate profit shifting on the budget of the Czech Republic" registered by the Czech Science Foundation under the registration number 18-14082S. This paper is based on a final thesis successfully defended at the Prague University of Economics and Business (Friedrich 2019). 


\section{JEL CODES}

H25, H26

\section{INTRODUCTION}

Due to the elimination of economic barriers along with the digitalization of the economy, it has become easier for multinational enterprises (MNEs) to shift taxable profits from one jurisdiction to another than it was in the past. One of the reasons is that businesses are no longer dependent on physical places (offices, factories, stores, etc.). Taxation, on the contrary, relies on the physical presence of businesses to a great extent. MNEs also have great resources at their disposal allowing them to seek optimal tax solutions by exploiting numerous double tax treaties and the differences between the tax systems of jurisdictions where they operate. This phenomenon is called base erosion and profit shifting (BEPS).

According to Buckley (1985), an MNE can be defined simply as an entity that "owns outputs of goods and services originating in more than one country". Entities may also be labeled as MNEs based on other criteria, e.g., by examining the international ownership structure of related entities, the number of foreign subsidiaries, etc.

MNEs are significant for the economy and the industry of the countries where they operate. Considering their size, MNEs also represent a significant source of tax revenues. Thus, countries are motivated to enter into tax competition with other countries or to offer preferential tax regimes to MNEs (Hines 2014). Even though an MNEs decision regarding which countries it operates in is not made solely based on tax preferences, it is well known that effective taxation is one of the criteria that play an important role when determining how and where to set up an international business (Tanzi 1996).

Despite intensive international efforts to hinder tax avoidance (projects such as BEPS Action Plan, or the European Union's Anti-Tax Avoidance Directive, ATAD), a significant corporate income tax (CIT) gap still exists. In 2014, the CIT gap from BEPS ranged from 4 to $10 \%$ of global CIT revenue (OECD 2015). Even though recent findings indicate that on average, tax avoidance in the EU may be decreasing over time (Thomsen - Watrin 2018; Murphy 2019), to close the CIT gap, countries need to learn which MNEs engage in BEPS as well as where and how the taxable profit is shifted.

This paper aims to identify the tendency of selected MNEs operating in the digital economy to shift profits from the Czech Republic with the intention of optimizing their global tax liability using a special indicator, the tax evasion rate (TER), proposed by Brada and Buus (2009). Since the method has not been tested on real world data yet, it is also the aim of this paper to demonstrate its potential as well as its limits. We supplement the TER method with a traditional benchmarking analysis using the OECDs transactional net margin method (TNNM).

Within social sciences, it has proven useful to use case studies when demonstrating that newly proposed and so far untested methods warrant further testing (Christians 2010). That is why we approach the problem with a set of case studies. Therefore, our results cannot provide general conclusions about profit shifting tendencies of all MNEs. The analysis and its results are nevertheless valuable for the critical assessment of the new method that can be discussed and used for further research. 
European branches of selected MNEs - Amazon, Apple, Avast, Google and Uber - have been used for the case studies. Data used is obtained from the Amadeus database and processed in $\mathrm{R}$ software. Potentially risky members of selected MNEs in the Czech Republic are identified and the setup of these members' transfer prices is assessed.

\section{LITERATURE REVIEW}

One should distinguish between tax planning, aggressive tax planning and tax evasion, even though the borderlines are often difficult to determine (e.g., Oats - Tuck 2019; Fuest - Riedel 2009). Tax planning is the form of tax optimization intended by the legislators. Aggressive tax planning is usually regarded as tax avoidance, which broadly speaking means playing by the rules given by law in a way that was not intended by the legislators. Direct violation of the rules given by law is regarded as tax evasion. It can be quite challenging to recognize aggressive tax planning, as vague terms like "fair share of tax" or "ethical aspects" are involved in the discussion (Datt 2014). Furthermore, due to the ambiguous definition and unintended nature of aggressive tax planning, it is even more challenging to estimate its extent. Still, there are studies that provide such estimates. According to Hines (2014), MNEs reallocate approximately two per cent of their taxable profits from high to low-tax jurisdictions using aggressive tax planning. According to UNCTAD (2015b), approximately 30\% of cross-border investment is directed through so called "conduit countries" before reaching the intended destination, which also points to the use of aggressive tax planning structures. Bradbury et al. (2018) provide several estimates of the extent of BEPS between 2012 and 2015 ranging from USD 80bn to 647bn. Cobham and Janský (2019) conclude that in 2012, as much as USD 660bn of taxable profit was shifted using aggressive tax planning structures; this corresponds to about $0.9 \%$ of world GDP.

Different approaches are used to identify and quantify aggressive tax planning. Broadly speaking, the approaches can be divided into two groups - macroeconomic approaches and microeconomic approaches. Studies using macroeconomic approaches often identify BEPS indirectly through foreign direct investments recorded in the balance of payments of countries. The relationship between foreign direct investments, the specifics of national tax systems and aggressive tax planning was researched for example by Castillo-Murciego and López-Laborda (2019), UNCTAD (2015a), the International Monetary Fund (2014) and Hajkova et al. (2006). In contrast, studies using microeconomic approaches rely on firm-level data (e.g., Fuest - Riedel 2012; Davies et al. 2015; Nerudová et al. 2020a and Vicard 2015).

Studies also focus on different strategies used by entities engaged in aggressive tax planning (Fuest - Riedel 2012) as well as the different channels used to shift profits. Such channels include debt financing (e.g., Huizinga et al. 2008; Buettner - Wamser 2013), royalty fee payments (e.g., Fuest et al. 2013; Evers - Spengel 2014) and transfer pricing (e.g., Davies et al. 2015; Vicard 2015).

Out of these channels, transfer pricing is a central focus of the current discussions about aggressive tax planning. The fact that 4 out of 15 actions proposed by the BEPS report (OECD 2016) are directly focused on transfer pricing highlights the need to develop new methods to better identify and quantify BEPS via transfer pricing, especially at the microeconomic level, to help tax authorities prevent such behavior. Our paper contributes to this discussion by testing a so far untested method (TER) proposed by Brada and Buus $(2009,2010)$ based on firm-level 
data over a series of case studies. By focusing our studies on the Czech Republic, we add to the existing literature covering profit shifting from the Czech Republic (e.g., Janský - Kokeš 2015, 2016). In a broader sense however, our approach may be applicable to other post-communist countries as well, especially the other members of the Visegrád Four (cf. Nerudová et al. 2020b) due to a high degree of similarity between their economies and their geopolitical closeness to the Czech Republic.

\section{DATA}

Five MNEs are chosen for our case studies based on several criteria ensuring their viability as research subjects; i.e., (i) the MNEs play a significant role in the digital economy, (ii) the MNEs have European branches - i.e., the MNEs operate in Europe, (iii) the MNEs also have members in the Czech Republic - i.e., the MNEs operate in the Czech Republic, (iv) for practical reasons, the European branches of the MNEs have no more than 150 members and a relatively simple ownership structure.

Not many MNEs fulfill all the criteria simultaneously. For example, Netflix operates in the Czech Republic; however, it has no Czech members. Another example is Sony, which has a Czech member, but its ownership structure is complex and its European branch has over 200 members. After careful consideration, Amazon, Apple, Avast, Google and Uber were chosen for our case studies since they fulfill all the criteria while also form a balanced group including larger and smaller MNEs as well as established and recently established MNEs alike.

Amazon is a technological giant best known for its online trading platform Amazon.com. It was founded in 1994 and is headquartered in Seattle, Washington. In FY 2019, Amazon's global revenues reached $\$ 280,522 \mathrm{~m}$ and it employed around 840,000 workers (as per the published FY 2019 annual report). Apple is another technology giant best known for its iPhone, iPad and Mac product lines. However, in recent years, the importance of its services (e.g., App Store, Apple Music, etc.) has been growing rapidly. Apple was founded in 1976 in Cupertino, California, where its current seat is also located. In 2019, Apple's global revenues reached $\$ 260,176 \mathrm{~m}$ and it employed around 137,000 workers (as per the published FY 2019 annual report). Avast is a Czech MNE focusing on cyber-security. It was founded in 1988 and has its headquarters in Prague. Interestingly, it did not have its initial public offering (IPO) until May 2018, up until which point it was owned privately. In 2019, Avast's global revenues reached $\$ 871 \mathrm{~m}$ and it employed around 1,700 workers (as per the published FY 2019 annual report). Google originally built its online empire around its signature search engine, but has since diversified into many other technological areas. Google was founded in 1998 and is headquartered in Mountain View, California. In 2019, Google's global revenues reached $\$ 161,857 \mathrm{~m}$ and it employed 118,899 workers (as per the published FY 2019 annual report). Uber is a shared-economy startup whose app has evolved from a ridesharing solution into a digital platform competing with traditional taxi services. It was founded in 2009 and has its headquarters in San Francisco, California. In 2019 , Uber's global revenues reached $\$ 14,147 \mathrm{~m}$ and it employed approximately 26,900 workers (as per the published FY 2019 annual report).

With the selection of MNEs concluded, we move on to obtaining data for our analysis. An initial sample containing financial information of all members of European branches of the chosen MNEs for FY 2015-2017 is obtained from the Amadeus database (data provided by 
Table 1. Data acquisition and elimination process

\begin{tabular}{|l|c|c|c|c|c|}
\hline Data acquisition and elimination process & Amazon & Apple & Avast & Google & Uber \\
\hline Initial sample before elimination & 114 & 29 & 15 & 61 & 36 \\
\hline Eliminated from sample & 76 & 11 & 9 & 40 & 15 \\
\hline - Members with incomplete financial data & 54 & 8 & 8 & 16 & 11 \\
\hline - Members of different branches & 14 & 1 & 0 & 3 & 0 \\
\hline - Members below materiality threshold & 7 & 2 & 0 & 21 & 4 \\
\hline - Members with anomalous tax rate & 1 & 0 & 1 & 0 & 0 \\
\hline Final sample after elimination & 38 & 18 & 6 & 21 & 21 \\
\hline
\end{tabular}

Source: Authors, based on data from the Amadeus database (by Bureau van Dijk).

Bureau van Dijk). We then reduce the initial sample to a final sample via an elimination process described below and summarized in Table 1.

Firstly, we exclude any members with incomplete or missing data on profit/loss (P/L) before tax, the amount of tax paid and P/L after tax for two or more FYs; the remaining financial data is averaged between the FYs. Next, ownership structures are identified in the sample and a controlling entity is found for each MNE where the ownership structure of the majority of the sample converges. A controlling entity can be either "local" (a European entity in the sample) or "global" (a non-European entity outside the sample). Members not belonging to the ownership structure - i.e., members with no relation to the controlling entity - are eliminated from the sample. This includes members belonging to a different branch of the same MNEs ownership structure. Finally, members below the materiality threshold (average after-tax P/L below EUR $500 \mathrm{~K})$ and members with anomalous tax rates (e.g., thousands of percent) are excluded. The final sample is described in Table 2.

From the final sample, two datasets are constructed for each MNE:

$D$ is a dataset containing information on average P/L before tax, average amount of tax paid and average $\mathrm{P} / \mathrm{L}$ after tax of each member of the MNE.

$\boldsymbol{M}$ is a dataset containing the ownership structure of the MNE (see below).

Additional financial data on independent comparables of selected Czech members of the chosen MNEs for FY 2015-2017 is also obtained from the Amadeus database for benchmarking purposes on an ad-hoc basis, as required for our case studies.

\section{METHODOLOGY}

For selected MNEs, we first calculate the TER indicator proposed by Brada and Buus (2009, 2010) by simulating optimal distribution of profits within MNEs and comparing it to real world data. We use a modified version of the indicator allowing us to overcome some of the original's limitations such as the inability to deal with negative tax losses and the fact that it results in corner solutions by assuming no limit to MNEs profit shifting ability. We achieve this by 
Table 2. Final sample of selected MNEs

\begin{tabular}{|l|c|c|c|c|c|}
\hline $\begin{array}{c}\text { Final sample of } \\
\text { selected MNEs }\end{array}$ & Amazon & Apple & Avast & Google & Uber \\
\hline $\begin{array}{l}\text { Local } \\
\text { controlling } \\
\text { entity }\end{array}$ & $\begin{array}{c}\text { Amazon Europe } \\
\text { Core Sarl }\end{array}$ & n.a. & $\begin{array}{c}\text { AVAST } \\
\text { PLC }\end{array}$ & n.a. & $\begin{array}{c}\text { Uber International } \\
\text { B.V. }\end{array}$ \\
\hline $\begin{array}{l}\text { Global } \\
\text { controlling } \\
\text { entity }\end{array}$ & $\begin{array}{c}\text { Amazon.com } \\
\text { Int'I Sales, Inc. }\end{array}$ & APPLE INC. & n.a. & Google LLC. & UBER \\
\hline Members & 38 & 18 & 6 & 21 & $\begin{array}{c}\text { INTERNATIONAL } \\
\text { C.V. }\end{array}$ \\
\hline $\begin{array}{l}\text { Countries } \\
\text { CZ, DE, FR, GB, }\end{array}$ & $\begin{array}{c}\text { BE, DE, DK, ES, FI, } \\
\text { IE, IT, LU, PL, SK IT, NL, PL, PT, } \\
\text { RU, SE }\end{array}$ & $\begin{array}{c}\text { GB, RS } \\
\text { FR, GB, IE, NL, PL, } \\
\text { RU, SE, UA }\end{array}$ & $\begin{array}{c}\text { AT, BE, GZ, GK, HR, IE, IT, } \\
\text { NL, NO, PL, PT, RO, } \\
\text { RU, SE, UA }\end{array}$ \\
\hline
\end{tabular}

Source: Authors, based on data from the Amadeus database (by Bureau van Dijk).

formulating several simple rules governing the MNEs profit shifting behavior when solving the optimization. We then use two additional TER-based indicators $(\overline{T O L}, \overline{T O P})$ to help identify profit shifting tendencies of individual members of the MNEs located in the Czech Republic.

To supplement the results, we follow up with an individual analysis of the transfer pricing setup of the Czech members using the OECDs TNNM and contrast our findings with the results provided by TER.

\subsection{Tax Evasion Rate (TER) method}

Brada and Buus (2009) use a simple mathematical model based on advanced linear algebra to describe how MNEs shift profits between countries with different levels of taxation to optimize their global after-tax profit using transfer pricing as the profit shifting channel. To quantify the tendency of MNEs to shift profits, Brada and Buus propose using an indicator, the TER obtained as a result of a series of optimization tasks of the MNEs behavior.

In their follow-up work, Brada and Buus (2010) also suggest that the specific places where profit shifting occurs within an MNE may be identified by examining the minimum and maximum solutions of the mathematical model and contrasting them to the real world distribution of profits within the MNE.

For our case studies, we use a modified version of the mathematical model proposed by Brada and Buus (2009) with the following basic objects:

$\boldsymbol{n} \quad$ is a scalar equal to the number of members of an MNE in the final sample.

$\boldsymbol{M}$ is an $n \times n$ matrix; $M=\left(m_{i, k}\right)$ describing the ownership structure of an MNE in the final sample ("share matrix"); data is obtained from dataset $M$. Element $m_{i, k}$ of $M$ denotes the share of member $i$ in member $k ; m_{i, k} \in 0 ; 1$. If the MNE has a local controlling entity, it is described by the first line of $M$. Diagonal values $m_{i, k}$ denote free shares not described by the share matrix, i.e., shares held by entities outside the share matrix. The free shares can be held either by a global controlling entity - as is the case in our case studies - or by other unrelated parties. 
$\overline{\boldsymbol{v}} \quad$ is a column vector denoting the free shares held by the global controlling entity in the members of the MNE (as described by $M$ ). In our case studies, all free shares - where applicable - are held by the global controlling entity; i.e., $\bar{v}=\overline{1}$.

$\boldsymbol{E} \quad$ is an $n \times n$ unit matrix used for calculation purposes; $E=\left(e_{i, k}\right) ; e_{k, k}=1$.

$\bar{l} \quad$ is a column vector used for summation purposes; $\bar{l}=\overline{1}$.

$\overline{\boldsymbol{t}}$ is a column vector denoting the corporate income tax rate $\left(t_{k}\right)$ of member $k$ of an MNE; $t_{k} \in\langle 0 ; 1\rangle$; data is obtained from the appropriate column of dataset $D$. For the sake of simplicity, it is assumed that only one tax rate exists (i.e., there are no differentiated tax rates, withholding tax rates or preferential tax treatment); $t_{k}$ is calculated as the average tax paid by member $k$ divided by the member's $\mathrm{P} / \mathrm{L}$ before tax.

$W$ is an $n \times n$ matrix with vector $\bar{t}$ on its diagonal used for calculation purposes; $W=\left(w_{i, k}\right)$; $w_{k, k}=t_{k}$.

$\bar{z} \quad$ is a column vector where element $z_{k}$ denotes the corporate income tax base of member $k$ of an MNE that is observed in reality; data is obtained from the appropriate column of dataset $D$. For the sake of simplicity, it is assumed that the corporate income tax base is equal to $\mathrm{P} / \mathrm{L}$ before tax (i.e., there are no adjustments to $\mathrm{P} / \mathrm{L}$ before tax, no accruals, etc.).

We also define the following functions and additional objects:

is a column vector of variables, where $x_{k}$ denotes the potential corporate income tax base of member $k$ after profit shifting took place. This vector serves as an input variable for all subsequent functions and optimization tasks.

$f_{\operatorname{tax}}(\bar{x}) \quad$ is a function which returns total tax paid by an MNE given the distribution of tax bases $\bar{x} ; f_{\operatorname{tax}}(\bar{x})=\bar{v}^{T} M W \bar{x}$.

$f_{\text {profit }}(\overline{\boldsymbol{x}}) \quad$ is a function which returns total P/L after tax of an MNE given the distribution of tax bases $\bar{x} ; f_{\text {profit }}(\bar{x})=\bar{v}^{T} M(E-W) \bar{x}$.

$f_{\text {con }}(\bar{x}) \quad$ is a constraint function which returns the sum of all elements in $\bar{x} ; f_{\text {con }}(\bar{x})=\bar{x}^{T} \bar{l}$.

$\boldsymbol{t}_{\operatorname{tax}} \quad$ is a scalar equal to the total tax paid by an MNE observed in the real world; data is obtained from the appropriate column of dataset $D$. Alternatively, it can be denoted as $t_{\operatorname{tax}}=f_{\operatorname{tax}}(\bar{z})=\bar{v}^{T} M W \bar{z}$.

$\boldsymbol{t}_{\text {net }} \quad$ is a scalar equal to total P/L after tax of MNE observed in the real world; data is obtained from the appropriate column of dataset $D$. Alternatively, it can be denoted as $t_{\text {net }}=f_{\text {profit }}(\bar{z})=\bar{v}^{T} M(E-W) \bar{z}$.

$\boldsymbol{t}_{\text {gross }} \quad$ is a scalar equal to total $\mathrm{P} / \mathrm{L}$ before tax of MNE observed in the real world; data is obtained from the appropriate column of dataset $D$. Alternatively, it can be denoted as $t_{\text {gross }}=\bar{l}^{T} M \bar{z}$.

The model allows us to find the distribution of tax liability and net profit ( $\mathrm{P} / \mathrm{L}$ after tax) between individual members of an MNE for any distribution of tax bases $\bar{x}$. It can also be used to determine such $\bar{x}$ where the MNE achieves the lowest and/or highest possible net profit by solving the following optimization tasks ( $\mathrm{R}$ package solnp is used for the optimization):

$$
\begin{gathered}
\bar{x}_{\max }=\min _{\bar{x}} f_{\operatorname{tax}}(\bar{x}) \\
\bar{x}_{\min }=\min _{\bar{x}} f_{\text {profit }}(\bar{x})
\end{gathered}
$$

With respect to constraints: 


$$
\begin{gathered}
f_{\text {con }}(\bar{x})=t_{\text {gross }} \\
\overline{l b} \leq \bar{x} \leq \overline{u b}
\end{gathered}
$$

where:

$\overline{\boldsymbol{x}}_{\max }$ is a column vector denoting such distribution of tax bases after profit shifting which maximizes the MNEs total net profit under the given constraints. However, since solnp package can only be used to find a minimum solution, the task is reformulated to finding a solution that minimizes the MNEs total tax (instead of maximizing its total net profit); i.e., $\bar{x}_{\max }=\max _{\bar{x}} f_{\text {profit }}(\bar{x})=\min _{\bar{x}} f_{\operatorname{tax}}(\bar{x})$.

$\overline{\boldsymbol{x}}_{\text {min }}$ is a column vector denoting such distribution of tax bases after profit shifting which minimizes the MNEs total net profit under the given constraints; i.e., $\bar{x}_{\min }=\min _{\bar{x}} f_{\text {profit }}(\bar{x})$.

$\overline{\mathbf{l b}}$ is a column vector representing the lower boundary of tax bases $\bar{x}$ required by the solnp package to solve the optimization tasks.

$\overline{\boldsymbol{u} \boldsymbol{b}}$ is a column vector representing the upper boundary of tax bases $\bar{x}$ required by the solnp package to solve the optimization tasks.

For the sake of simplicity, Brada and Buus (2010) do not allow members of MNEs to have negative tax bases (or negative tax paid) and assume that there is no limit to an MNEs capacity

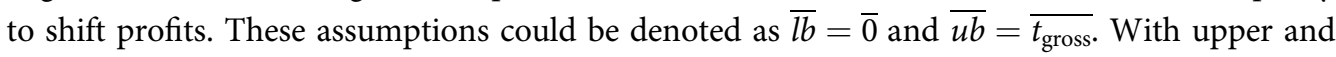
lower boundaries set this way, the whole profit of an MNE could be shifted to the member with the highest/lowest taxation resulting in corner solutions of the optimization tasks.

Corner solutions, however, do not usually reflect the economic reality of profit shifting. Furthermore, we have encountered multiple entities in the final sample exhibiting negative tax bases and/or negative tax. To better reflect the economic reality of profit shifting and to avoid unsubstantiated exclusion of members exhibiting tax losses from the final sample, we set the upper and lower boundaries in the following way:

a) Let us denote a constant shift $=\alpha \times t_{\text {gross }} ; \alpha \in\left(0 ; 1>\right.$; $t_{\text {gross }}>0$; where $\alpha$ is a coefficient quantifying the capacity of an MNE to shift profits. Constant shift represents the part of MNEs total tax base that can be shifted to a single member from other members and vice versa.

Note: MNEs cannot usually shift their total tax base due to various transactional barriers (e.g., transfer pricing regulations, the risk of tax audits, etc.) and other economic factors. In our model, MNEs are only allowed to shift profit by the amount of "shift".

b) For member $k$ of an MNE: if $z_{k} \geq 0$ and at the same time $t_{k} \geq 0$, the boundaries are set to $l b_{k}$ $=\max \left(0 ; z_{k}-\right.$ shift $) ; u b_{k}=z_{k}+$ shift.

Note: If both the tax base and the tax rate observed in reality are positive, it is undesirable for MNEs to shift profits away from member $k$ in a way that would create a tax loss since this could potentially alarm the tax authorities. When decreasing the tax base of member $k$, the MNE is therefore limited by zero and its capacity to shift profits. When increasing the tax base of member $k$, the MNE is limited only by its capacity to shift profits. 
c) For member $k$ of an MNE: if $z_{k} \geq 0$ and at the same time $t_{k} \geq 0$, the boundaries are set to $l b_{k}$ $=\max \left(0 ; z_{k}-\right.$ shift $) ; u b_{k}=z_{k}$.

Note: If the tax base is positive and the tax rate is negative, it is undesirable for MNEs to create a tax loss in member $k$ for the same reasons as described in $b$ ). When decreasing the tax base of member $k$, the MNE is therefore limited by zero and its capacity to shift profits. Increasing the tax base would ad absurdum lead to a lower tax liability; when increasing the tax base, the MNE is therefore limited by the tax base observed in reality. The same applies to 0\% tax rates.

d) For member $k$ of an MNE: if $z_{k}<0$ and at the same time $t_{k} \geq 0$, the boundaries are set to $l b_{k}$ $=z_{k} ; u b_{k}=z_{k}+$ shift.

Note: If the tax base is negative (i.e., the member has a tax loss) and the tax rate is positive, it is undesirable for MNEs to create additional tax loss in member $k$ for the same reasons as described in situation $b$ ). When decreasing the tax base of member $k$, the MNE is therefore limited by the tax loss observed in reality. When increasing the tax base of member $k$, the MNE is limited only by its capacity to shift profits.

e) For member $k$ of an MNE: if $z_{k} \leq 0$ and at the same time $t_{k} \leq 0$, the boundaries are set to: $l b_{k}=z_{k} ; u b_{k}=\min \left(0 ; z_{k}+\right.$ shift $)$.

Note: If the tax base is negative (i.e., the member has a tax loss) and the tax rate is also negative, it is undesirable for MNEs to create additional tax loss in member $k$ for the same reasons as described in situation $b$ ). When decreasing the tax base of member $k$, the MNE is therefore limited by the tax loss observed in reality. Increasing the tax base above zero would ad absurdum lead to a lower tax liability; when increasing the tax base of member $k$, the MNE is therefore limited by zero as well as its capacity to shift profits. The same applies to $0 \%$ tax rates.

We stress that even the above-mentioned rules represent a substantial simplification of the economic reality of profit shifting. We therefore recommend further research of MNEs profit shifting behavior that would result in a more comprehensive ruleset.

Finally, the TER as well as two other vector indicators can be constructed from the results of the optimization tasks:

$$
\begin{gathered}
\text { TER }=\frac{t_{\text {net }}-f_{\text {profit }}\left(\bar{x}_{\text {min }}\right)}{f_{\text {profit }}\left(\bar{x}_{\max }\right)-f_{\text {profit }}\left(\bar{x}_{\text {min }}\right)} ; \text { TER } \in\langle 0 ; 1\rangle \\
\overline{T O L}=\bar{x}_{\text {min }}-\bar{x}_{\max } \\
\overline{T O P}=\bar{x}_{\text {min }}-\bar{z}
\end{gathered}
$$

where:

TER is the "Tax Evasion Rate", an indicator that quantifies the degree of similarity between an MNEs net profit observed in reality and the maximum net profit achievable by an MNE by profit shifting (with the minimum achievable net profit used as a zero point). This indicator can be interpreted as the perceived tendency of an MNE to shift its global profits to members with lower taxation using transfer pricing. 


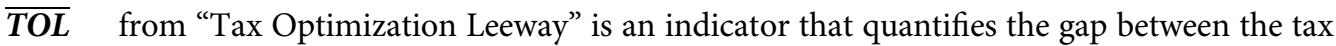
bases minimizing the net profit $\left(\bar{x}_{\min }\right)$ of an MNE and the tax bases maximizing its net profit $\left(\bar{x}_{\max }\right) . \overline{T O L}$ can be used to pinpoint specific members of the MNE where profit shifting could occur ("risky members"). For risky member $r$ of the MNE: $T O L_{r} \gg 0$.

$\overline{\mathbf{T O P}}$ from "Tax Optimum Proximity" is an indicator that quantifies the proximity of the actual distribution of tax bases of an MNE observed in reality to the distribution of tax bases maximizing its net profit (or in other words the distance of the actual distribution $\bar{z}$ from the distribution minimizing the MNEs net profit $\left.\bar{x}_{\min }\right)$. Similarly to $\overline{T O L}, \overline{T O P}$ can be used to pinpoint specific members of the MNE where profit shifting could occur (risky members). For risky member $r$ of the MNE: TOP $r \gg 0$.

\subsection{Transactional Net Margin Method (TNNM)}

A more traditional approach to assessing whether an MNE engages in profit shifting requires examining its transfer pricing setup using one of OECDs traditional methods (the comparable uncontrolled price method, the cost plus method, the resale price method) or transactional profit methods (the transactional net margin method, the transactional profit split method). The OECDs approach involves performing a benchmarking analysis to find arm's length prices that would be charged in transactions between unrelated parties and contrasting these prices with the prices charged by MNEs on intragroup transactions (OECD 2017).

We chose the TNNM to supplement the results of the TER method by analyzing the transfer pricing setup of Czech members of MNEs (analyzed members). While most of the OECDs methods rely on non-public information about the operations of MNEs (e.g., pricing policies and detailed accounting data), TNNM may be applied using only publicly available data.

Rather than benchmarking the prices of individual transactions, TNNM benchmarks a suitable profit level indicator of comparable independent entities (comparables). We chose earnings before interest and taxes (EBIT) margin as our profit level indicator as it has a reasonable predictive power for our case studies and the data needed for its calculation is readily available: $\mathrm{EBIT}$ margin $=\mathrm{EBIT} /$ total revenues; EBIT margin $\in\langle 0 ; 1\rangle$.

We select the initial sample of comparables using a search strategy consisting of multiple fixed and variable criteria. Fixed criteria (i.e., criteria common for all analyzed members) are: (i) EU28 region, (ii) BvD Independence indicator A-, A or A+, and (iii) financial data available for FY 2015-2017. Variable criteria (i.e., criteria varying between analyzed members) are (i) relevant NACE code, (ii) total revenues between approximately 0.25-4 times that of the analyzed member, and (iii) total assets between approximately $0.25-4$ times that of the analyzed member.

We then exclude entities with missing data on EBIT and total revenues from the initial sample. We also exclude entities with losses in two or more FYs - a common step to ensure comparability (Solilová - Nerudová 2019). The remaining financial data is averaged between the FYs. Next, we exclude any entities engaging in substantially different activities than the analyzed member (such entities are often present in the sample despite the initially applied NACE criteria). Entities with unavailable or unreachable websites are automatically eliminated. Finally, we increase the comparability of the sample by eliminating extreme values - i.e., entities with EBIT margins outside the interquartile range - as recommended by Feinschreiber (2004). The remaining comparables represent the arm's length range of EBIT margin. 


\subsection{Our approach}

To test whether the chosen MNEs shift profits from the Czech Republic to countries with lower taxation and to test the TER method on real world data, we have devised the following approach to our case studies combining the TER method with TNNM:

a) First, TER of chosen MNEs is calculated.

- If $T E R \in\langle 0,5 ; 1\rangle$, it is assumed that the tendency of the MNE to shift its global profits may be significant, and the MNE is therefore subject to further analysis aimed at determining whether the global tendency manifests itself in the Czech Republic.

- If TER $\in<0 ; 0,5)$, it is assumed that the tendency of the MNE to shift its global profits is not significant enough for further analysis.

b) Where TER $\in 0,5 ; 1, \overline{T O L}$ and $\overline{T O P}$ are calculated to determine whether an MNEs Czech member is a risky member potentially shifting profits from the Czech Republic.

- If for member $r: T O L_{r} \gg 0$ and at the same time $T O P_{r} \gg 0$, it is suspected that member $r$ is the MNEs risky member and it is subject to further analysis to confirm the initial suspicion.

- Otherwise, member $r$ does not arise suspicion of being the MNEs risky member. It is therefore determined that the MNEs global profit shifting tendency does not manifest itself in the Czech Republic.

c) Risky Czech members of MNEs which arise suspicion are subject to benchmarking analysis using TNNM to assess whether the risky member's transfer pricing setup complies with the arm's length principle.

- If for member $r$ the EBIT margin falls outside the interquartile (arm's length) range, it is assumed that the suspicion regarding the risky member $r$ has been confirmed and that the MNE has a tendency to shift profits from the Czech Republic.

- Otherwise, it is assumed that the suspicion regarding the risky member $r$ has not been confirmed. It is therefore determined that the MNEs global profit shifting tendency does not manifest itself in the Czech Republic.

\section{RESULTS}

In the first step, we calculate TER for all chosen MNEs. Because $\alpha$ cannot be easily observed in reality and/or accurately estimated from real world data, we calculate $T E R$ five times for $\alpha \in\{0,2 ; 0,4 ; 0,6 ; 0,8 ; 1\}$ with the following results (Table 3 ).

We stress that TER values should not be interpreted as an exact and final quantification of an MNEs profit shifting tendencies/risk, but rather as an indication that such risks may exist (i.e., that the MNE may be motivated to shift profits). For example assuming that Amazon has the capacity to shift $40 \%$ of its total profit $(\alpha=0.4)$, then the observed distribution of net profit between Amazon's members corresponds to the ideal distribution (i.e., the distribution maximizing Amazon's total net profit and minimizing total tax) from $68 \%(T E R=0.68)$. This information is, however, insufficient to draw conclusions about whether Amazon engages in profit shifting or not. TER should always be interpreted with the broad economic reality in mind and should be supported by other methods. Below, we interpret the average TER values listed in Table 3. 
Table 3. Tax Evasion Rate (TER) of selected MNEs

\begin{tabular}{|l|c|c|c|c|c|}
\hline TER calculation & Amazon & Apple & Avast & Google & Uber \\
\hline TER value for $\alpha=0.2$ & 0.62 & 0.73 & 0.42 & 0.85 & 0.56 \\
\hline TER value for $\alpha=0.4$ & 0.68 & 0.78 & 0.31 & 0.90 & 0.55 \\
\hline TER value for $\alpha=0.6$ & 0.70 & 0.82 & 0.25 & 0.92 & 0.54 \\
\hline TER value for $\alpha=0.8$ & 0.71 & 0.85 & 0.22 & 0.93 & 0.54 \\
\hline TER value for $\alpha=1.0$ & 0.71 & 0.87 & 0.23 & 0.93 & 0.54 \\
\hline Average TER value & 0.68 & 0.81 & 0.29 & 0.91 & 0.55 \\
\hline
\end{tabular}

Source: Authors, based on data from the Amadeus database (by Bureau van Dijk).

Avast exhibits by far the lowest TER (0.29), and therefore the lowest global tendency to shift profits. The low tendency may be attributed - for example - to: (i) the relatively small size of Avast compared to the other MNEs (Avast has only 6 members in CZ, UK, and RS), which may prevent extensive profit shifting; (ii) the relatively low revenues of Avast compared to other MNEs potentially rendering complicated and expensive profit shifting structures unfeasible; (iii) the fact that Avast was owned privately by Czech owners until May 2018 which may have resulted in a decreased motivation to shift profits from the Czech Republic; and (iv) the fact that Avast's services are not very diversified, limiting the number of profit shifting channels. The lack of profit shifting is also evidenced by the fact that the majority of Avast's total net profit is achieved by one of its Czech members despite this member exhibiting the highest tax rate (i.e., Avast's profit is being accumulated in the Czech Republic despite higher taxation).

Uber exhibits the second lowest TER (0.55) which slightly exceeds the chosen cut-off value (0.5), making Uber subject to further analysis. We point out that Uber's global profit shifting tendency is higher than Avast's but still significantly lower than that of the other MNEs (i.e., medium). This may be attributed - for example - to: (i) the relatively low revenues of Uber compared to other MNEs (except for Avast), making complicated and expensive profit shifting structure potentially unfeasible; (ii) the fact that Uber was owned privately until May 2019; and (iii) the fact that compared to Avast, Uber's revenues are an order of magnitude higher which could explain the higher global profit shifting tendency.

Amazon exhibits higher TER than previous MNEs (0.68) making it subject to further analysis. The increase in TER over Avast and Uber could be attributed - for example - to: (i) the absence of certain limitations present in Avast and (to a lower extent) Uber; and (ii) the fact that Amazon is a publicly traded company motivated to increase shareholder value. We note that Amazon's global profit shifting tendency is still considerably lower than Apple's and Google's (which are similar in size to Amazon); we therefore denote it as medium.

Apple exhibits the second highest TER (0.81) which indicates a high global profit shifting tendency. This would make Apple subject to further analysis; however, Apple's Czech member was eliminated from the final sample because it falls below the materiality threshold (i.e., its net profit is below EUR 500K). Furthermore, the Czech member engages in R\&D activities subsidized by the Czech government, resulting in a negative tax liability as well as a negative tax rate of 
Table 4. Tax Optimization Leeway (TOL) and Tax Optimum Proximity (TOP) of selected MNEs

\begin{tabular}{|c|c|c|c|}
\hline TOL, TOP calculation & Amazon CZ & Google CZ & Uber CZ \\
\hline \multicolumn{4}{|l|}{ TOL and TOP values for $\alpha=0.2$} \\
\hline TOL value & 35,417 & 0 & 10,678 \\
\hline TOP value & 31,246 & -797 & 10,621 \\
\hline TOL $\gg>0$ and TOP $\gg 0$ & yes & no & yes \\
\hline \multicolumn{4}{|l|}{ TOL and TOP values for $\alpha=0.4$} \\
\hline TOL value & 66,663 & 0 & 10,678 \\
\hline TOP value & 62,492 & -797 & 10,621 \\
\hline TOL $\gg 0$ and TOP $\gg 0$ & yes & no & yes \\
\hline \multicolumn{4}{|l|}{ TOL and TOP values for $\alpha \quad 0.6$} \\
\hline TOL value & 87,799 & 0 & 10,678 \\
\hline TOP value & 83,628 & -797 & 10,621 \\
\hline TOL $\gg>0$ and TOP $>>0$ & yes & no & yes \\
\hline \multicolumn{4}{|l|}{ TOL and TOP values for $\alpha=0.8$} \\
\hline TOL value & 10,770 & 0 & 10,678 \\
\hline TOP value & 6,599 & -797 & 10,621 \\
\hline TOL $\gg 0$ and TOP $\gg 0$ & yes & no & yes \\
\hline \multicolumn{4}{|l|}{ TOL and TOP values for $\alpha=1.0$} \\
\hline TOL value & 0 & 0 & 0 \\
\hline TOP value & $-4,171$ & -797 & -57 \\
\hline TOL $\gg>0$ and TOP $\gg 0$ & no & no & no \\
\hline \multicolumn{4}{|l|}{ Summary } \\
\hline Number of positive results & 4 & 0 & 4 \\
\hline Suspicion about profit shifting & yes & no & yes \\
\hline
\end{tabular}

Source: Authors, based on data from the Amadeus database (by Bureau van Dijk); TOL and TOP values are listed in thousands of EUR.

approximately -15\%; this would suggest that Apple is motivated to shift profits to the Czech Republic from other countries (to benefit from the subsidy) rather than the other way around. Thus, it seems improbable that Apple is shifting profits from the Czech Republic via the Czech member.

Google exhibits the highest TER (0.91) which indicates high global profit shifting tendencies and makes Google subject to further analysis. Similarly to Apple and Amazon, this tendency might be explained - for example - by: (i) the absence of economic and other limitations preventing profit shifting; and (ii) the fact that it is a publicly traded company (see above for 
more details). Additionally, a certain tendency to shift profits from the Czech Republic may be indicated by the Czech member's high tax rate (almost 37\%).

Based on our TER calculation, we assume that 4 out of the 5 chosen MNEs (Amazon, Apple, Google and Uber) may have significant tendencies to shift their global profits. These results are generally in line with our expectations based on several recent high-profile cases covered by the media.

The global profit shifting tendency might be stronger in Amazon, Apple and Google than in Uber, whose average TER is close to the cut-off value (0.5). Avast's global profit shifting tendency is not significant enough for further analysis. Each of the remaining MNEs has exactly one Czech member in the final sample (except for Apple which is not subject to further analysis as explained above): Amazon Logistic Prague s.r.o. (Amazon CZ), Google Czech Republic s.r.o. (Google CZ) and Uber Czech Republic Technology s.r.o. (Uber CZ).

In the second step, we calculate Tax Optimization Leeway (TOL) and Tax Optimum Proximity (TOP) values for the Czech members of the remaining MNEs. Similarly to TER, TOL and TOP were calculated 5 times for $\alpha \in\{0,2 ; 0,4 ; 0,6 ; 0,8 ; 1\}$. Only members where $r$ exhibits $T O L_{r} \gg 0$ and $T O P_{r} \gg 0$ for the majority of $\alpha$ tested (i.e., at least 3 positive results out of 5) are considered to be risky members. The results are shown in Table 4.

Based on our TOL and TOP calculation, Amazon CZ and Uber CZ are suspected to be risky Czech members of Amazon and Uber respectively that may be used to shift profits from the Czech Republic. The risky members are subject to further analysis. On the other hand, Google $\mathrm{CZ}$ does not arise suspicion and is probably not used to shift profits from the Czech Republic despite the fact that TER implies a high global profit shifting tendency.

In the third step, we perform a benchmarking analysis of the risky members using TNNM. The variable criteria for Amazon CZ are: (i) NACE codes 521, 5,224, 5,229; (ii) total revenues between EUR 37.5m-600m; and (iii) total assets between EUR $20 \mathrm{~m}-320 \mathrm{~m}$. The variable criteria for Uber CZ are (i) NACE code 4,932; (ii) total revenues between EUR 125K-2m; and (iii) total assets between EUR $31 \mathrm{~K}-500 \mathrm{~K}$. The final sample contains five comparables for each risky member. The results of the benchmark are summarized in Table 5.

Table 5. Transactional Net Margin Method (TNNM) benchmark of risky members

\begin{tabular}{|l|c|c|}
\hline TNNM benchmark & Amazon $\mathbf{C Z}$ & Uber $\mathbf{C Z}$ \\
\hline EBIT margin of the risky member & $2.82 \%$ & $7.91 \%$ \\
\hline Interquartile range & $3.44-4.85 \%$ & $3.80-12.21 \%$ \\
\hline Minimum & $3.44 \%$ & $3.80 \%$ \\
\hline 1st quartile & $3.59 \%$ & $5.68 \%$ \\
\hline Median & $3.65 \%$ & $6.19 \%$ \\
\hline 3rd quartile & $3.85 \%$ & $9.10 \%$ \\
\hline Maximum & $4.85 \%$ & $12.21 \%$ \\
\hline Within interquartile range & no & yes \\
\hline
\end{tabular}

Source: Authors, based on data from Amadeus database (by Bureau van Dijk). 
Based on the results of the benchmark, we consider the suspicion that Amazon may be shifting profits from the Czech Republic via Amazon CZ to be confirmed. However, Amazon's tendency to do so may not be very high based on the relatively small difference $(0.62 \%)$ between the EBIT margin of Amazon CZ (2.82\%) and the minimum arm's length value (3.44\%); we denote it as medium tendency. We point out that should a less restrictive approach be used to eliminate extreme values from the final sample (e.g., 1st and 9th decile range instead of an interquartile range), the EBIT margin of Amazon CZ would fall within the arm's length range.

As for Uber CZ, our suspicion regarding possible profit shifting by Uber from the Czech Republic via Uber CZ has not been confirmed; the EBIT margin of Uber CZ (7.91\%) is well in line with its peers. We therefore conclude that Uber exhibits a low tendency to shift profits from the Czech Republic. Our conclusion is further supported by the fact that TER implies only a limited global profit-shifting tendency to begin with.

All interim results of our case studies are summarized in Table 6.

Table 6. Summary of interim results

\begin{tabular}{|c|c|c|c|c|c|}
\hline & Amazon & Apple & Avast & Google & Uber \\
\hline \multicolumn{6}{|l|}{ a) TER calculation } \\
\hline Average TER & 0.68 & 0.81 & 0.29 & 0.91 & 0.55 \\
\hline TER $>0.5$ & yes & Yes & No & yes & yes \\
\hline Further analysis & yes & $n o^{a}$ & No & yes & yes \\
\hline \multicolumn{6}{|l|}{ b) TOL, TOP calculation } \\
\hline Czech member & $\begin{array}{l}\text { Amazon Logistic } \\
\text { Prague s.r.o. }\end{array}$ & - & - & $\begin{array}{l}\text { Google Czech } \\
\text { Republic. s.r.o. }\end{array}$ & $\begin{array}{c}\text { Uber Czech Republic } \\
\text { Tech. s.r.o. }\end{array}$ \\
\hline $\begin{array}{l}\text { Suspicion about profit } \\
\text { shifting }\end{array}$ & Yes & - & - & No & Yes \\
\hline \multicolumn{6}{|l|}{ c) TNMM benchmark } \\
\hline $\begin{array}{l}\text { EBIT margin of Czech } \\
\text { member }\end{array}$ & $2.82 \%$ & - & - & - & $7.91 \%$ \\
\hline Interquartile range & $3.44-4.85 \%$ & - & - & - & $3.80-12.21 \%$ \\
\hline $\begin{array}{l}\text { Within interquartile } \\
\text { range }\end{array}$ & No & - & - & - & Yes \\
\hline \multicolumn{6}{|l|}{ Final assessment } \\
\hline $\begin{array}{l}\text { Profit shifting } \\
\text { tendency - global }\end{array}$ & High & High & Low & High & Medium \\
\hline $\begin{array}{l}\text { Profit shifting } \\
\text { tendency - CZ }\end{array}$ & Medium & Low & Low & Low & Low \\
\hline
\end{tabular}

Source: Authors, data compiled from Tables 1-6.

${ }^{\mathrm{a}}$ Czech member not available. 


\section{CONCLUSIONS}

The aim of the paper was to identify the tendencies of selected MNEs to engage in BEPS using the TER indicator. As we are not aware of the TER method being applied in practice yet, we wanted to test its suitability for BEPS indication on a sample of selected MNEs using the case study method.

After testing the TER method on real world data, we arrive at the conclusion that it might serve as an efficient tool for preliminary indication of MNEs potential tendencies to engage in BEPS via transfer mispricing. However, to achieve more reliable results, TER needs to be interpreted in a broader economic context and supplemented by other methods.

Our results also suggest that the tendency to use transfer mispricing for shifting taxable profit might be correlated with the size and the form of ownership of MNEs. However, this conclusion cannot be drawn solely based on our case studies and requires further research.

We have identified several limitations that need to be considered when using the TER method. First, it is not clear how to interpret non-extreme values of TER (i.e., values that are not close to 0 or 1); we therefore established our own criteria for interpretation of such non-extreme values. For further development of the TER method, possible common interpretation rules should be researched. Second, our assumptions about the profit shifting behavior of MNEs (represented by the upper and lower boundaries $\overline{l b}$ and $\overline{u b}$ and parameter $\alpha$ ) are not based on empirical evidence. Thus, our assumptions might not properly reflect the economic reality of BEPS. Third, the tax system is described by one parameter only - the tax rate - despite the fact that MNEs are known to consider other parameters of tax systems as well when choosing whether and how to engage in BEPS. Additional characteristics of tax systems should be analyzed to further increase the predictive power of the TER the method. Lastly, the Amadeus dataset used for our analysis has several natural limitations. Since Amadeus only contains data on European entities, it is not suitable to assess BEPS tendencies on a truly global scale. Furthermore, the dataset only contains information on accounting P/L before rather than the actual tax base while in reality these two values can differ significantly. These limitations of the Amadeus dataset can be addressed for example by using Orbis datasets with worldwide coverage, or using data from country by country reports (CbCR) containing information on actual tax bases of MNEs.

The limitations also apply to TNNM; EBIT margin used as the profit level indicator might be affected by influences other than BEPS. The predictive power of TNNM can be further limited by using a suboptimal search strategy. Nevertheless, TNNM is a generally accepted method for transfer pricing benchmarks. Its undeniable advantage lies in its data availability as well as its applicability across different economic sectors.

Tax authorities might benefit the most from the application of the TER method. Since the application of the TER method can be fully automatized, it could be used for the preliminary indication of BEPS risks in MNEs across the board and for subsequent targeting of tax audits with only initial administrative (programming) costs. Furthermore, tax authorities have suitable non-public datasets at their disposal (e.g., CbCR data and data derived from the international exchange of tax information) which should increase the predictive power of the results. However, the above-mentioned limitations of the TER method must be considered and the results need to be interpreted carefully. 


\section{REFERENCES}

Brada, J. - Buus, T. (2009): Detection of Possible Tax-Evasive Transfer Pricing in Multinational Enterprises. European Financial and Accounting Journal 4(2): 65-78.

Brada, J. - Buus, T. (2010): Searching for Potential Tax-Evasive Transfer Pricing in Multinational Enterprises: A Mathematical Approach. Prague: University of Economics.

Buettner, T. - Wamser, G. (2013): Internal Debt and Multinational Profit Shifting: Empirical Evidence from Firm-Level Panel Data. National Tax Journal 66(1): 63-96.

Bradbury, D. - Hanappi, T. - Moore, A. (2018): Estimating the Fiscal Effects of Base Erosion and Profit Shifting: Data Availability and Analytical Issues. Transnational Corporations 25(2), 91-106.

Buckley, P. J. (1985): A Critical View of Theories of Multinational Enterprise. In: Buckley, P. J. - Casson, M. (Eds.): The Economic Theory of The Multinational Enterprise. London: Macmillan.

Castillo-Murciego, Á. - López-Laborda, J. (2019): The Effect of Double Taxation Treaties and Territorial Tax Systems on Foreign Direct Investment: Evidence for Spain. Economics E-Journal 13(22), 1-33.

Christians, A. (2010): Case Study Research and International Tax Theory. St. Louis Law Journal 55(1): 332-366.

Cobham, A. - Janský, P. (2019): Measuring Misalignment: The Location of US Multinationals' Economic Activity versus the Location of their Profits. Development Policy Review 37(1): 91-110.

Datt, K.H. (2014): Paying a Fair Share of Tax and Aggressive Tax Planning - A Tale of Two Myths. eJournal of Tax Research 12(2), 410-432.

Davies, R. - Martin, J. - Parenti, M. - Toubal, F. (2015): Knocking on Tax Haven's Door: Multinational Firms and Transfer Pricing. The Review of Economics and Statistics 100(1): 120-134.

Evers, L. - Spengel, C. (2014): In: Effective Tax Rates Under IP Tax Planning. ZEW - Centre for European Economic Research Discussion Paper No. 14-111.

Feinschreiber, R. (2004): Transfer Pricing Methods: An Applications Guide. Hoboken, N.J.: Wiley.

Friedrich, M. (2019): Sklon nadnárodních entit k přesouvání ziskỉ [Tendency of multinational entities to shift profits]. Prague: University of Economics.

Fuest, C. - Riedel, N. (2009): Tax Evasion, Tax avoidance and Tax Expenditures in Developing Countries: A Review of the Literature. Oxford: Oxford University.

Fuest, C. - Riedel, N. (2012): Tax Evasion and Tax Avoidance: The Role of International Profit Shifting. In: Reuter, P. (Ed.): Draining Development? Controlling Flows of Illicit Funds from Developing Countries. Washington, DC: World Bank.

Fuest, C. - Spengel, C. - Finke, K. - Heckemeyer, J. - Nusser, H. (2013): In: Profit Shifting and "Aggressive” Tax Planning by Multinational Firms: Issues and Options for Reform. ZEW - Centre for European Economic Research Discussion Paper No. 13-078.

Hajkova, D. - Nicoletti, G. - Vartia- Yoo, L. Kwang-Yeol (2016): Taxation, Business Environment and FDI Location in OECD Countries. OECD Working Paper No. 502.

Hines, J.R. (2014): How Serious a Problem is Base Erosion and Profit Shifting? Canadian Tax Journal 62(2), 442-453.

Huizinga, H. - Laeven, L. - Nicodeme, G. (2008): Capital Structure and International Debt Shifting. Journal of Financial Economics 88(1): 80-118.

International Monetary Fund, 2014. In: Spillovers in International Corporate Taxation. Washington D.C.: International Monetary Fund.

Janský, P. - Kokeš, O. (2015): Corporate Tax Base Erosion and Profit Shifting out of the Czech Republic. Post-Communist Economies 27(4): 537-546. 
Janský, P. - Kokeš, O. (2016): Profit-shifting from the Czech Multinational Companies to European Tax Havens. Applied Economic Letters 23(16): 1-4.

Murphy, R. (2019): The European Tax Gap. A report for the Socialists and Democrats Group in the European Parliament. https://www.socialistsanddemocrats.eu/sites/default/files/2019-01/the_european_ tax_gap_en_190123.pdf, accessed 07/10/2020.

Nerudová, D. - Solilová, V. - Litzman, M. - Janský, P. (2020a): International Tax Planning within the Structure of Corporate Entities Owned by the Shareholder-individual through Panama Papers Destinations. Development Policy Review 38(1): 124-139.

Nerudová, D. - Dobranschi, M. - Solilová, V. - Litzman, M. (2020b): Profit Shifting to Onshore and Offshore Tax Havens: the Case of Visegrad Countries. Post-Communist Economies 32(7): 904-946.

Oats, L. - Tuck, P. (2019): Corporate Tax Avoidance: is Tax Transparency the Solution? Accounting and Business Research 49(5): 565-583.

OECD (2015): Measuring and Monitoring BEPS, Action 11 - 2015 Final Report, OECD/G20 Base Erosion and Profit Shifting Project. Paris: OECD Publishing.

OECD (2016): BEPS Project Explanatory Statement: 2015 Final Reports, OECD/G20 Base Erosion and Profit Shifting Project. Paris: OECD Publishing.

OECD (2017): OECD Transfer Pricing Guidelines for Multinational Enterprises and Tax Administrations 2017. Paris: OECD Publishing.

Solilová, V. - Nerudová, D. (2019): Transferové ceny - Unikátní komplexní zpracování problematiky/ Praktické pojetí formou prípadových studii [Transfer pricing - Unique complex work on the topic/ Practical approach in the case study form]. Prague: Wolters Kluwer ČR.

Tanzi, V. (1996): Globalization, Tax Competition and the Future of Tax Systems. Washington D.C.: International Monetary Fund.

Thomsen, M. - Watrin, C. (2018): Tax Avoidance over Time: A Comparison of European and U.S. Firms. Journal of International Accounting, Auditing and Taxation 33: 40-63.

UNCTAD (2015a): FDI, Tax and Development: The Fiscal Role of Multinational Enterprises: Towards Guidelines for Coherent International Tax and Investment Policies. UNCTAD Investment and Enterprise Division Working Paper 3/26/2015.

UNCTAD (2015b): World Investment Report 2015: Reforming International Investment Governance. Geneva: UNCTAD.

Vicard, V. (2015): Profit Shifting Through Transfer Pricing: Evidence from French Firm Level Trade Data. Banque de France Working Paper No. 555.

Open Access. This is an open-access article distributed under the terms of the Creative Commons Attribution-NonCommercial 4.0 International License (https://creativecommons.org/licenses/by-nc/4.0/), which permits unrestricted use, distribution, and reproduction in any medium for non-commercial purposes, provided the original author and source are credited, a link to the CC License is provided, and changes - if any - are indicated. 